\title{
OXIDATION OF MCRALY COATINGS ON NI-BASED SUPERALLOYS
}

\author{
M. T. Pace ${ }^{1}$, R. C. Thomson ${ }^{1}$ and J Wells ${ }^{2}$ \\ ${ }^{1}$ Institute of Polymer Technology and Materials Engineering, Loughborough University, Loughborough, LE11 3TU, UK \\ ${ }^{2}$ RWE npower plc, Windmill Hill Business Park, Whitehill Way, Swindon, SN5 6PB, UK
}

Keywords: MCrAlY, Bond Coat, Oxidation

\begin{abstract}
This research is concerned with advanced characterisation of thermally grown oxides (TGO) on MCrAlY bond coats with differing chemical compositions. The purpose of the research is to develop an improved understanding of TGO growth and related failure mechanisms aimed at enhancing the lifetime prediction methods for coated blade systems used in industrial power generation. It is shown that a continuous alumina layer forms on a NiCoCrAlY bond coat comprising primarily of the $\beta$ and $\gamma$ phases, whereas a two layer oxide, rich in both chromium and aluminium respectively, is formed on a NiCrAlY bond coat which contains the $\gamma^{\prime}$ and $\beta$ phases. In both cases, the grain structures within the TGO are extremely fine, and additional complex precipitates are found only within the alumina.
\end{abstract}

\section{Introduction}

Industrial gas turbines can achieve greater thermodynamic efficiency if the operating temperature is increased $d^{[1-3]}$. Therefore, the resultant increase in operating temperatures has led to turbine blades now seeing temperatures of $\sim 900^{\circ} \mathrm{C}$ in power generation units. Turbine blade alloys require not only excellent high temperature strength ${ }^{[2,4]}$ but also good oxidation and corrosion resistance. Nickel-based superalloys are commonly used in conjunction with a coating system to fulfil these requirements. Commonly MCrAlY coatings are applied to the superalloy substrate for increased oxidation and corrosion resistance, often in conjunction with a ceramic thermal barrier coating (TBC) to enable performance to higher temperatures in hostile environments.

Thermal spray processes such as plasma spraying are regularly used to apply MCrAlY coatings. The spray process can greatly affect the time to failure of a coating, with variables such as coating thickness, porosity and interface quality being important ${ }^{[5]}$. The coating composition will also affect the nature of the oxide formation on the coating, and therefore its ability to protect the component during service.

The ' $\mathrm{M}$ ' in the MCrAlY coating is typically $\mathrm{Ni}$ and/or Co, with Co being added to improve the hot corrosion resistance (in conjunction with $\mathrm{Cr}$ ) and also to enhance coating ductility. Protection of the underlying substrate arises from the formation of protective oxides, generally either $\mathrm{Al}_{2} \mathrm{O}_{3}$ or $\mathrm{Cr}_{2} \mathrm{O}_{3}{ }^{[6]}$, from interaction with the high temperature environment. In order for these oxides to provide sufficient protection they need to be continuous, slow growing, stable and adherent. The performance of an MCrAlY coating can be greatly affected by it's composition. A reservoir of aluminium is needed such that $\mathrm{Al}_{2} \mathrm{O}_{3}$ is able to form and consequently aluminium is an essential element. Chromium can also be added to improve the corrosion resistance. Cobalt containing coatings are preferred where hot corrosion and/or sulphidation are an issue because in general cobalt-based alloys have a higher resistance to sulphidation than nickel-based alloys ${ }^{[1]}$. Reactive elements, such as yttrium or rhenium, are also routinely added as they are thought to increase the adhesion of the oxide scale ${ }^{[7-8]}$. Several theories have been put forward about the mechanisms behind this, with most focusing on the modification of Al transport in the alloy ${ }^{[9]}$, such as 'pegging mechanisms', altered growth mechanisms and increased oxide plasticity ${ }^{[7]}$. Reactive elements are also thought to alter the transport mechanism by reducing the transport of the native $\mathrm{Al}$ and $\mathrm{Cr}$ cations, thereby changing the growth mechanism to inward oxygen anion transport leading to a reduced scale growth ${ }^{[10-14]}$.

This paper discusses the influence of MCrAlY composition on microstructural development in blade coating systems. The differences in phase stability as a function of composition are considered in two coatings, and the subsequent difference in the composition and morphology of the TGO. The influence of ageing time and temperature on microstructural development will be considered. The results are discussed in the context of possible growth and failure mechanisms for the TGO.

\section{Experimental Procedure}

Two different MCrAlY coatings were investigated in this study - a NiCoCrAlY and a NiCrAlY, both on an IN738 substrate; compositions are provided in Table I. Both were manufactured using low pressure plasma sprayed (LPPS) onto a conventionally cast nickel-based superalloy with an air plasma sprayed (APS) 8 wt.\% yttria stabilised zirconia thermal barrier coating (TBC) applied on top. Samples were in the form of test coupons onto which the coatings were deposited using production process parameters to ensure similarity to production components. The thickness of the MCrAlY coatings varied quite significantly between the two sets of samples. The average thickness for both the bond coat and TBC can be seen in Table II. After an appropriate coating diffusion treatment, these samples were then exposed to a range of isothermal heat treatments in air.

Table I: Compositions for the two different MCrAlY bond coats

\begin{tabular}{|c|c|c|c|c|c|}
\multicolumn{2}{|c}{ wt $\%$} \\
\hline \hline Coating name & Ni & Co & Cr & Al & Y \\
\hline \hline NiCoCrAIY & 47.5 & 22.0 & 17.0 & 13.0 & 0.5 \\
\hline NiCrAIY & 67.0 & - & 22.0 & 10.0 & 1.0 \\
\hline \hline
\end{tabular}

Table II: Comparison of layer thickness between bond coats

\begin{tabular}{||c|c|c|}
\hline Coating & Bond Coat Thickness & TBC Thickness \\
\hline \hline NiCoCrAIY & $230-260 \mu \mathrm{m}$ & $220-230 \mu \mathrm{m}$ \\
\hline NiCrAIY & $80-90 \mu \mathrm{m}$ & $190-200 \mu \mathrm{m}$ \\
\hline
\end{tabular}

Thermodynamic calculations were performed using the software package, MTDATA ${ }^{[15]}$ developed by the National Physical Laboratory, in conjunction with the Ni-data ${ }^{[16]}$ thermodynamic database. The relevant phases present within the database for the elements $\mathrm{Ni}, \mathrm{Co}, \mathrm{Cr}$ and $\mathrm{Al}$ in the coating were liquid, $\gamma, \gamma^{\prime}, \beta, \sigma$ 
and bec chromium. Yttrium was not accounted for in these calculations as the database was primarily designed for nickelbased superalloys with lower Al concentrations, rather than coating compositions. Nevertheless, the results obtained provide a useful insight into the phases likely to be present at equilibrium in these materials, and in general show good agreement with experimental observations.

A Leo 1530 VP field emission gun scanning electron microscope (FEGSEM) was used for microstructural characterisation, using the backscattered electron imaging mode (BSE). An EDAX Pegasus combined energy dispersive $\mathrm{x}$-ray (EDX) and electron backscattered electron diffraction (EBSD) system attached to the FEGSEM was utilised for quantitative chemical analysis. The EBSD data analysis software used was OIM4, with chemical indexing (ChI-Scan) capability which allows the allowed phases to be refined on the basis of chemical composition. The phase data used within the software are provided in Table III.

Table III: Phase data used during EBSD scans

\begin{tabular}{||c|c|c||}
\hline Phase & Lattice Parameter & Crystal Structure \\
\hline Gamma $(\gamma)$ & 3.52 & fcc \\
\hline Gamma Prime $\left(\gamma^{\prime}\right)$ & 3.572 & Ordered fcc $\left(\mathrm{Ll}_{2}\right)$ \\
\hline Beta $(\boldsymbol{\beta})$ & 2.88 & Ordered fcc \\
\hline $\boldsymbol{\alpha}$-Cr & 2.88 & fcc \\
\hline
\end{tabular}

A dual beam focused ion beam scanning electron microscope (FIBSEM) was employed to create transmission electron microscope (TEM) samples from site specific regions of the coating and oxide. The FIBSEM used was an fei Nova Nanolab 600 dual beam. In order to produce a TEM sample, two trenches were milled either side of a point of interest, resulting in a thin section. This section was then cut, leaving it attached only by one small point. A micro-manipulator was manoeuvred into the sample and attached by joining it to the thin section with a deposit of platinum. The remaining section was subsequently cut, freeing the sample, which was then removed with the micro-manipulator. The sample was attached onto a copper grid, again using platinum. The sample was then finally thinned using the ion beam until it was electron transparent. These samples were examined using a JEOL JEM 2000FX TEM, fitted with an Oxford Instruments Inca EDX system.

\section{Results}

\section{Thermodynamic Modelling}

Thermodynamic calculations were performed to investigate the equilibrium phases present in the two bond coats as a function of temperature over the temperature range $500-1400^{\circ} \mathrm{C}$. Predicted phase fractions and compositions were then examined in detail at the experimental ageing temperatures $\left(940^{\circ} \mathrm{C}\right.$ and $\left.975^{\circ} \mathrm{C}\right)$, which were chosen to be representative of service temperatures.

NiCoCrAlY The results of the thermodynamic calculations are presented in Figure 1. It can be seen that the $\beta$ phase dominates over the temperature range, in amounts ranging from $50-80 \% . \gamma^{\prime}$ and $\sigma$ were predicted to coexist with the $\beta$ phase at lower temperatures. The $\gamma^{\prime}$ phase gives way to the $\gamma$ phase above $\sim 800^{\circ} \mathrm{C}$, and the $\sigma$ phase disappears above $\sim 950^{\circ} \mathrm{C}$. This indicates that over the temperatures of interest, this MCrAlY composition is a typical two phase $\beta$ and $\gamma$ coating.
The phase percentages predicted for an ageing temperature of $940^{\circ} \mathrm{C}$ can be seen in Table IV. Similar results are obtained for $975^{\circ} \mathrm{C}$, with the coating predicted to contain a large amount of $\beta$ and a smaller amount of $\gamma$ in both cases. At $940^{\circ} \mathrm{C}$, the coating is also predicted to contain a very small amount ( $\sim 3 \mathrm{wt} . \%)$ of sigma phase. This phase was not observed experimentally, but is likely to occur only after prolonged ageing.

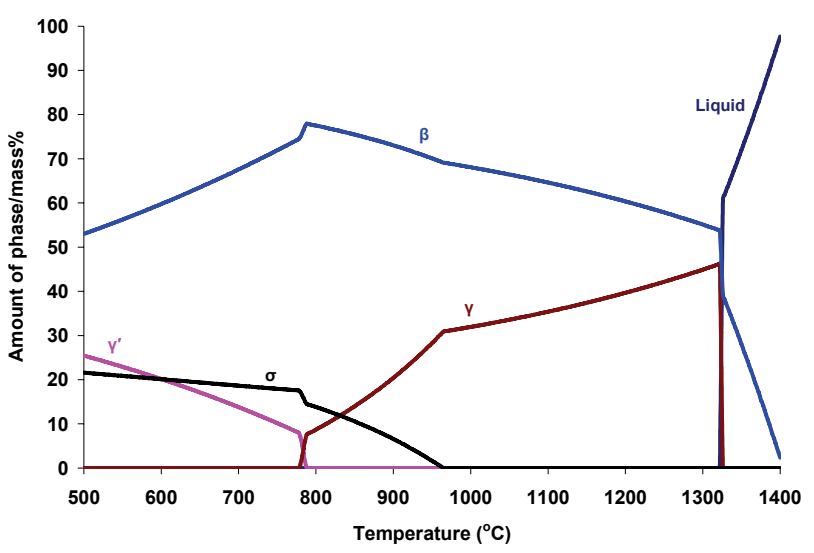

Figure 1: Predicted phase map for a NiCoCrAlY bond coat

Table IV: Predicted phase proportions and compositions for a $\mathrm{NiCoCrAlY}$ bond coat at $940^{\circ} \mathrm{C}$

\begin{tabular}{||c|c|c|c|c|c||}
\hline \multirow{2}{*}{ Phase } & $\begin{array}{c}\text { Phase amount at } \\
\mathbf{9 4 0}^{\circ} \mathbf{C}(\%)\end{array}$ & \multicolumn{4}{|c||}{ Composition (wt.\%) } \\
\cline { 3 - 6 } & 70.7 & $\mathbf{N i}$ & $\mathbf{C o}$ & $\mathbf{C r}$ & $\mathbf{A l}$ \\
\hline Beta $(\boldsymbol{\beta})$ & 26.6 & 34.4 & 18.7 & 9.75 & 17.1 \\
\hline Gamma $(\boldsymbol{\gamma})$ & 2.7 & 9.4 & 29.9 & 60.7 & 0.0 \\
\hline Sigma $(\boldsymbol{\sigma})$ & \multicolumn{3}{|l}{} \\
\hline
\end{tabular}

An EBSD scan of the sample aged at $940^{\circ} \mathrm{C}$ for $2100 \mathrm{~h}$ (Figure 2) shows that the microstructure does indeed to comprise of the two phases: $\gamma$ and $\beta$. The phase map has been produced using $\mathrm{ChI}$ Scan which additionally links the composition of the phases to the diffraction patterns. Therefore, the $\beta$ phase has been additionally discriminated using the difference in the $\mathrm{Al}$ content. (a)

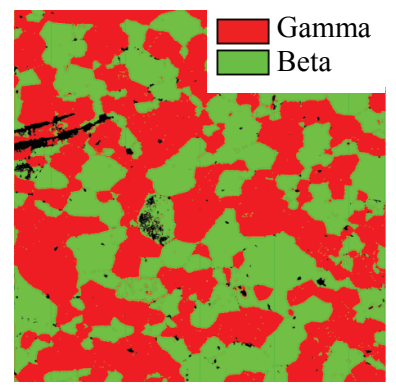

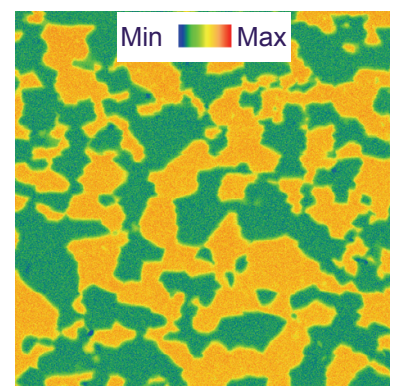

(b)
Figure 2: EBSD Map of a NiCoCrAlY bond coat at $940^{\circ} \mathrm{C}$ showing (a) phase map and (b) EDX map for $\mathrm{Al}$

In order to compare the predictions of phase composition with the measured values, EDX measurements were taken of individual phases. A comparison is presented in Table $\mathrm{V}$ for the sample aged for $2000 \mathrm{~h}$ at $940^{\circ} \mathrm{C}$. It can be seen that there is reasonable agreement, especially bearing in mind that the calculations represent equilibrium conditions and do not include yttrium. 
Table V: Comparison of predicted and measured phase compositions for a NiCoCrAlY sample aged for $2000 \mathrm{~h}$ at $940^{\circ} \mathrm{C}$

\begin{tabular}{|c|c|c|c|c|c|c||}
\hline \hline Composition (wt.\%) $\rightarrow$ & \multirow{2}{*}{ Al } & Cr & Co & Ni & Y \\
\hline Source Data & Phase & & & & & \\
\hline $\begin{array}{c}\text { Thermodynamic } \\
\text { Calculations }\end{array}$ & Gamma $(\gamma)$ & 3.3 & 31.8 & 30.0 & 34.8 & 0.0 \\
\cline { 2 - 7 } & Beta $(\boldsymbol{\beta})$ & 17.1 & 9.75 & 18.7 & 54.4 & 0.0 \\
\hline $\begin{array}{c}\text { EDX Spot } \\
\text { Measurements }\end{array}$ & Gamma $(\gamma)$ & 6.0 & 21.7 & 25.3 & 46.3 & 0.6 \\
\cline { 2 - 7 } & Beta $(\boldsymbol{\beta})$ & 16.9 & 7.3 & 13.7 & 61.4 & 0.5 \\
\hline \hline
\end{tabular}

NiCrAlY The results of the thermodynamic calculations are presented in Figure 3. In this case, the dominant phase below $\sim 975^{\circ} \mathrm{C}$ was $\gamma^{\prime}$, coexisting with up to $20 \% \alpha-\mathrm{Cr}$ and small amounts of $\beta$. A sharp discontinuity was observed at approximately $975^{\circ} \mathrm{C}$, with the stable phases above this temperature changing to be $\gamma$, with smaller amounts of $\beta$ up to $\sim 30 \%$. This means that at lower temperatures the common two phase $\beta$ and $\gamma / \gamma^{\prime}$ phase structure will not be present, with the coating apparently being susceptible to phase changes over the temperature range of interest.

Table VI: Predicted phase proportions and composition for a $\mathrm{NiCrAlY}$ bond coat at $940^{\circ} \mathrm{C}$

\begin{tabular}{|c|c|c|c|c||}
\hline \hline \multirow{2}{*}{ Phase } & $\begin{array}{c}\text { Phase amount } \\
\text { at } \mathbf{9 4 0} \mathbf{C}^{\circ} \mathbf{C}(\%)\end{array}$ & \multicolumn{3}{|c|}{ Composition (wt.\%) } \\
\cline { 3 - 5 } & 7.22 & $\mathbf{N i}$ & $\mathbf{C r}$ & $\mathbf{A l}$ \\
\hline Beta $(\boldsymbol{\beta})$ & 79.54 & 78.4 & 9.7 & 17.2 \\
\hline Gamma Prime $\left(\boldsymbol{\gamma}^{\prime}\right)$ & 13.24 & 2.6 & 97.4 & 0.0 \\
\hline $\begin{array}{c}\text { Alpha Chromium } \\
(\boldsymbol{\alpha} \text {-Cr) }\end{array}$ & \multicolumn{3}{|l}{} \\
\hline
\end{tabular}

At the ageing temperature of $940^{\circ} \mathrm{C}$ the microstructure would therefore be expected to consist of a $\gamma^{\prime}$ matrix, with some $\alpha-C r$ and $\beta$ present. The phase amounts predicted for an ageing temperature of $940^{\circ} \mathrm{C}$ can be seen in Table VI. The $\gamma^{\prime}$ and $\beta$ phases can be differentiated by their $\mathrm{Al}$ contents, although it is interesting to note that the predicted $\mathrm{Cr}$ concentration is similar in both phases.

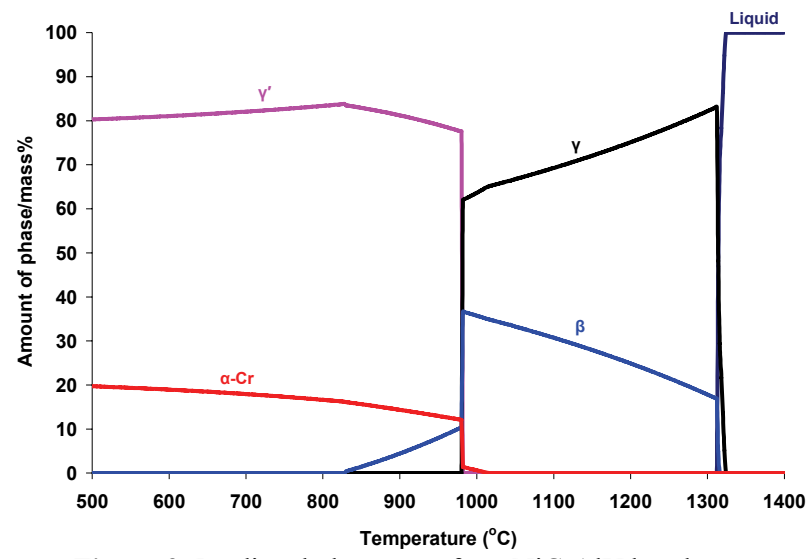

Figure 3: Predicted phase map for a NiCrAlY bond coat

An EBSD scan of the $2000 \mathrm{~h}$ at $940^{\circ} \mathrm{C}$ sample (Figure 4) shows that the microstructure comprises, as predicted of a three phase $\gamma^{\prime}$, $\beta, \alpha-\mathrm{Cr}$ mixture. The phase map has been produced using the $\mathrm{ChI}$ Scan technique. It can also be seen that in this particular case the bond coat exhibits a degree of inhomogeneity.

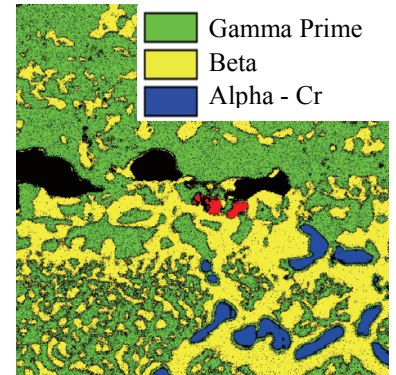

(a)

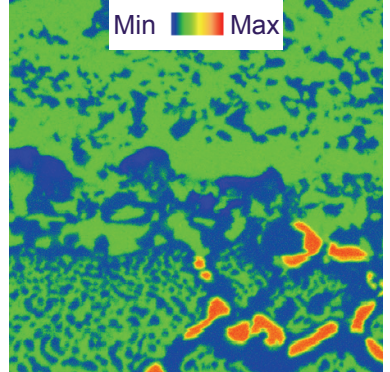

(b)
Figure 4: EBSD Map of a NiCrAlY bond coat at $940^{\circ} \mathrm{C}$ showing (a) phase map and (b) EDX map for $\mathrm{Cr}$

Chemical composition measurements were also made from individual phases using EDX analysis in the SEM to allow comparison of the predicted and measured compositions. The results are presented in Table VII. It can be seen that, as previously noted for the NiCoCrAlY coating, there is reasonable agreement between the measured and predicted values.

Table VII: Comparison of predicted and measured phase compositions for a NiCrAlY sample aged for $2000 \mathrm{~h}$ at $940^{\circ} \mathrm{C}$

\begin{tabular}{|c|c|c|c|c|c|}
\hline \multicolumn{2}{|c|}{ Composition (wt.\%) $\rightarrow$} & \multirow{2}{*}{ Al } & \multirow{2}{*}{$\mathbf{C r}$} & \multirow{2}{*}{$\mathbf{N i}$} & \multirow{2}{*}{ Y } \\
\hline Source Data & Phase & & & & \\
\hline \multirow{3}{*}{$\begin{array}{c}\text { Thermodynamic } \\
\text { Calculations }\end{array}$} & Gamma Prime $\left(\gamma^{\prime}\right)$ & 11.0 & 10.6 & 78.4 & 0.0 \\
\hline & Beta $(\beta)$ & 17.2 & 9.7 & 73.1 & 0.0 \\
\hline & $\begin{array}{c}\text { Alpha Chromium } \\
(\alpha-\mathrm{Cr})\end{array}$ & 0.0 & 97.4 & 2.6 & 0.0 \\
\hline \multirow{3}{*}{$\begin{array}{c}\text { EDX Spot } \\
\text { Measurements }\end{array}$} & Gamma Prime $\left(\gamma^{\prime}\right)$ & 7.52 & 17.8 & 74.6 & 0.1 \\
\hline & Beta $(\beta)$ & 17.9 & 7.3 & 74.7 & 0.1 \\
\hline & $\begin{array}{c}\text { Alpha Chromium } \\
(\alpha-C r)\end{array}$ & 0.4 & 93.0 & 5.9 & 0.7 \\
\hline
\end{tabular}

\section{Microstructural Characterisation}

The samples were analysed using a combination of electron microscopy techniques, including scanning electron microscopy using primarily EDX and EBSD to quantify the composition and identity of the phases present, and transmission electron microscopy using site-specific samples prepared using a FIBSEM. The detailed microstructural analyses are presented below for unaged (i.e. after the coating diffusion treatment but with no subsequent isothermal ageing), short and long term aged samples of each of the NiCoCrAlY and NiCrAlY samples respectively.

\section{NiCoCrAlY}

Unaged: The NiCoCrAlY samples also contain a key coat sprayed between the bond coat and the TBC. The key coat is applied in order to increase the adhesion of the TBC to the bond coat. The key coat is of the same composition as the bond coat but is usually sprayed with a larger particle size in order to increase the surface roughness, thereby improving the mechanical keying of the TBC. An overview of the system detailing the various layers can be seen in Figure 5. Using backscattered imaging it is possible to identify the two phase structure of the bond coat and key coat (Figure $5 \mathrm{~b}$ ), as predicted by the thermodynamic calculations. The higher surface roughness of the key coat can also be seen in the micrographs. The bond coat has a reasonably consistent thickness and is quite thick at $\sim 250 \mu \mathrm{m}$. The TBC shows a large crack 

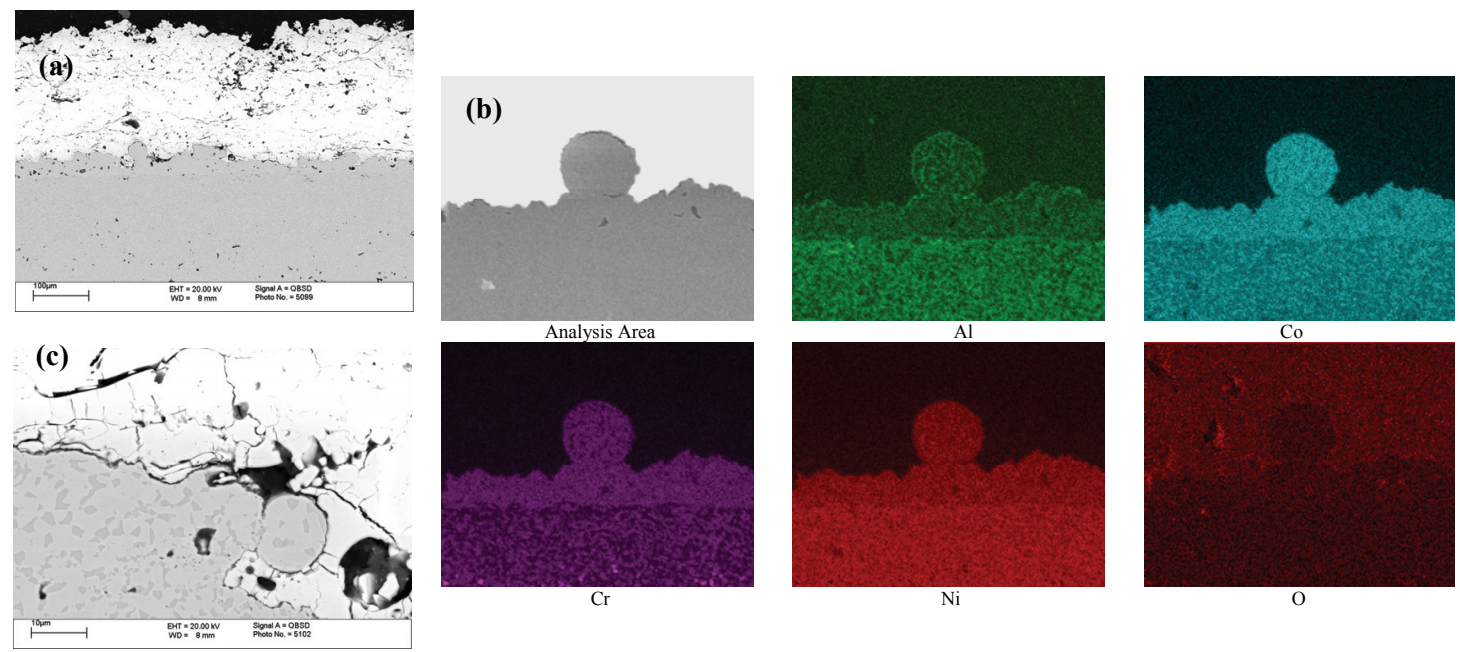

Figure 5: An unaged NiCoCrAlY bond coat/TBC interface region (a) and (b) Backscattered SEM images (c) chemical composition maps

network present, in addition to some voids. It is possible that some of the voids are due to pullout during mechanical polishing however, there is substantial porosity within the TBC. The crack network is largely due to the nature of the spray process. Figure $5 \mathrm{c}$ presents chemical composition maps of the unaged NiCoCrAlY sample. The $\beta$ phase in the bond coat (high aluminium) sits within a $\gamma$ matrix (high in $\mathrm{Co}, \mathrm{Cr}$ and $\mathrm{Ni}$ ). Correlating the EDX maps to the micrographs indicates that the dark phase seen is $\beta$. The structure of the key coat is the same as the bond coat, apart from a smaller overall grain size, most probably due to a higher cooling rate during spraying.
EBSD analysis was used to analyse the grain structures at the bond coat/key coat/TBC interface. The bond coat and key coat grain sizes are quite variable. Some of the $\gamma$ grains also display twinning. The TBC is extremely heterogeneous with a hugely variable and complex grain structure. The spray process itself will introduce a variability in cooling within each molten splat but these splats are also impacting at different sites which also affects the splat size and cooling rate. These factors produce a grain size within the TBC which varies from being sub-micron up to tens of microns in size. It is important to note that no oxide is visible at the key coat/TBC interface from the spray process.
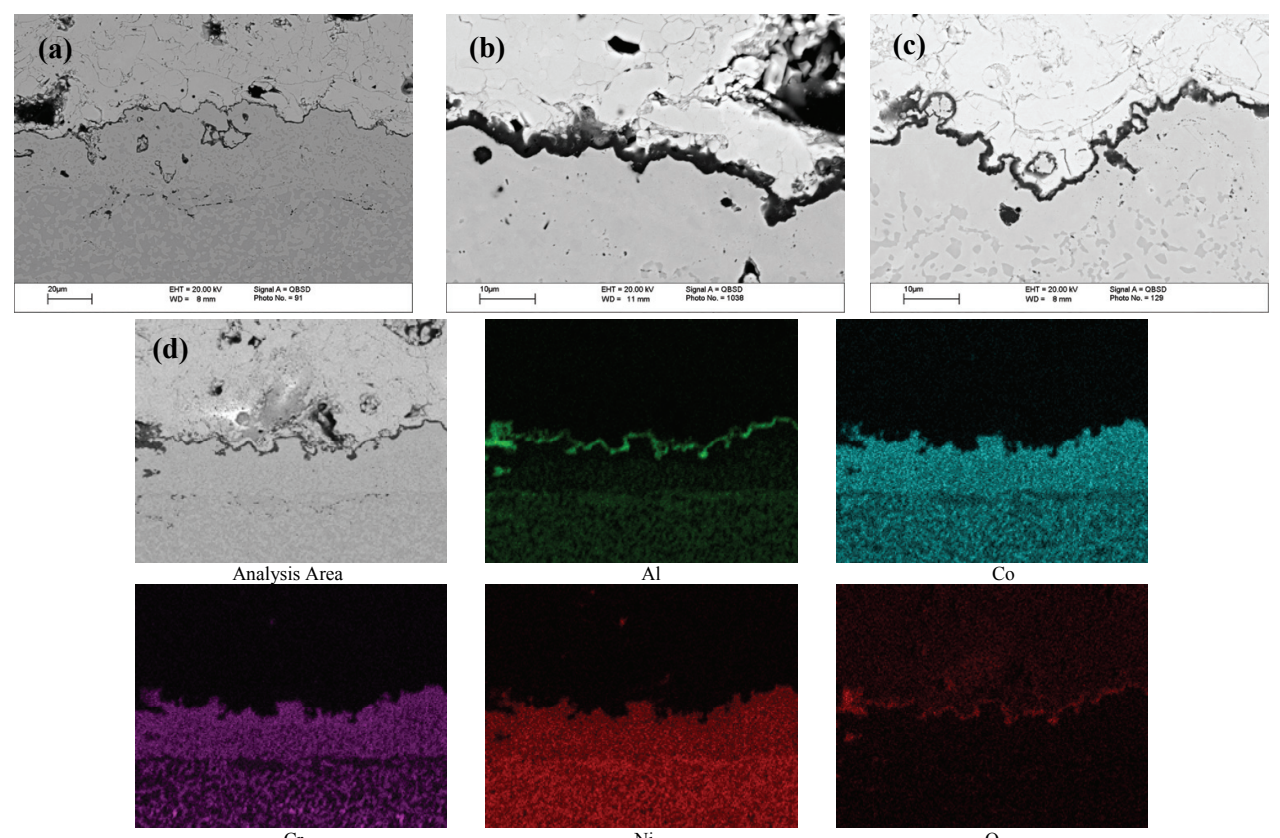

$\mathrm{Cr}$

$\mathrm{Ni}$

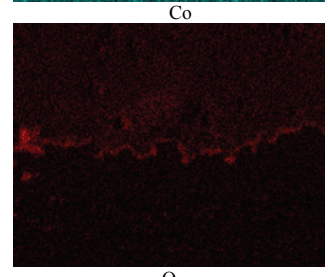

Figure 6: Backscattered SEM images showing a NiCoCrAlY sample aged for (a) $1 \mathrm{~h}$ (b) $10 \mathrm{~h}$ (c) $100 \mathrm{~h}$ and (d) chemical composition maps of the $10 \mathrm{~h}$ sample 
Short Term Oxidation: Samples were aged isothermally at $940^{\circ} \mathrm{C}$ in air and examined after $1 \mathrm{~h}, 10 \mathrm{~h}$, and $100 \mathrm{~h}$ intervals. After ageing significant microstructural change begins to occur in the samples. After $1 \mathrm{~h}$ an aluminium rich oxide (presumably alumina) has formed at the key coat/TBC interface, it is initially very thin (less than a micron) but is continuous along the sample. Very little depletion of the $\beta$ phase is seen at this stage due to the small volume of aluminium diffusion. As the ageing time increases however, the thickness of both the oxide layer and the $\beta$ depletion in the key coat increase. After $10 \mathrm{~h}$ the oxide is approximately 1 $\mu \mathrm{m}$ thick and the $\beta$ depletion layer is approximately $10 \mu \mathrm{m}$ thick throughout the sample.
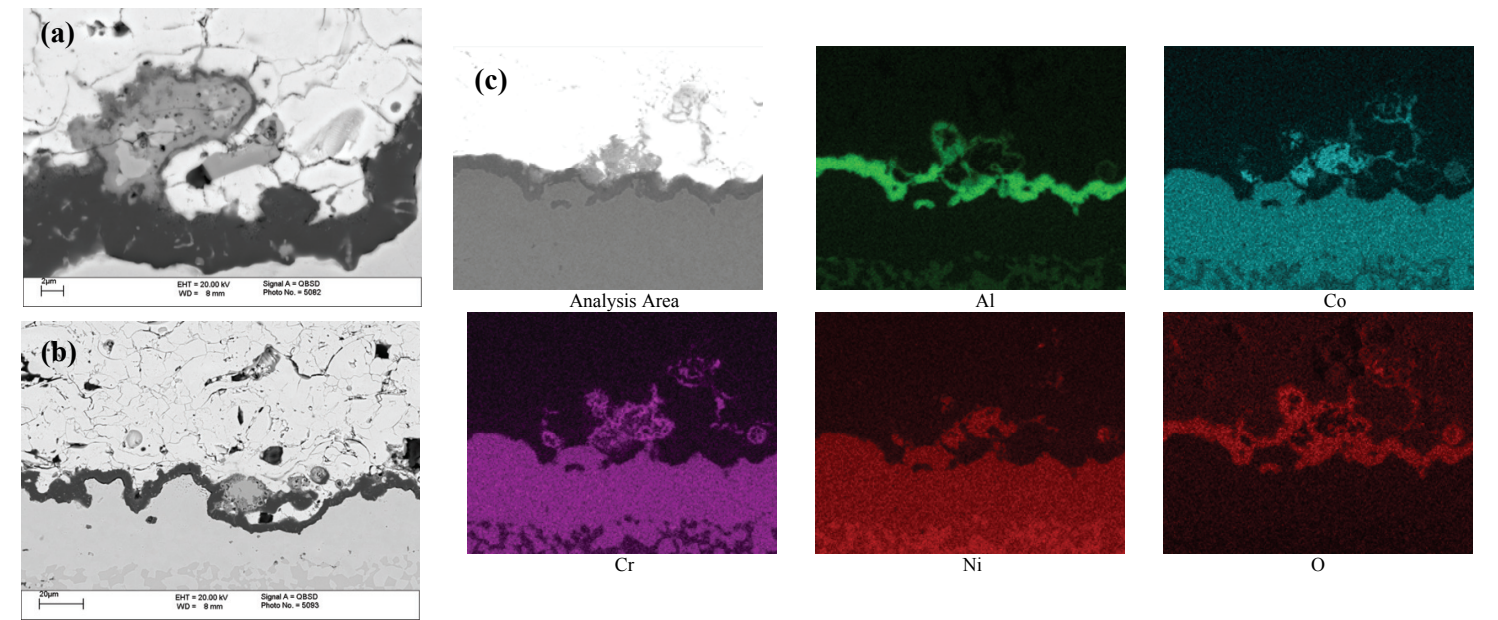

Figure 7: A NiCoCrAlY bond coat/TBC interface region aged for $2000 \mathrm{~h}$ at $940^{\circ} \mathrm{C}$ (a) and (b) Backscattered diffraction SEM images (c) chemical composition map

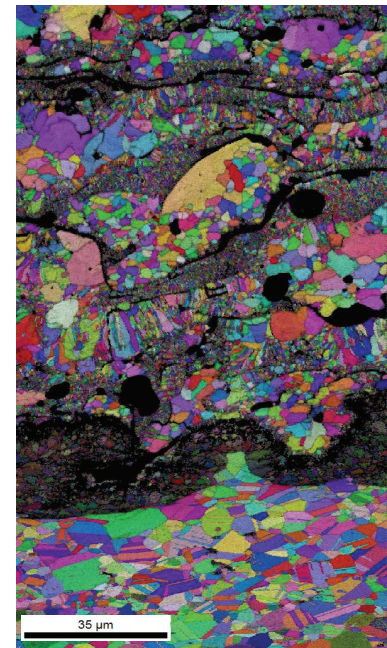

(a)
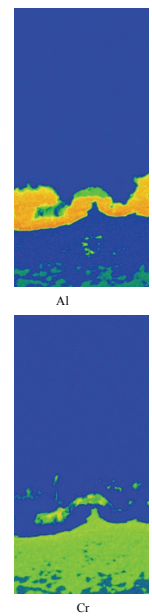

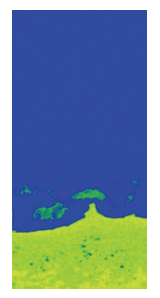
$\mathrm{Ni}$

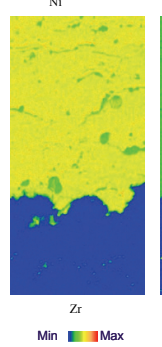

(b)

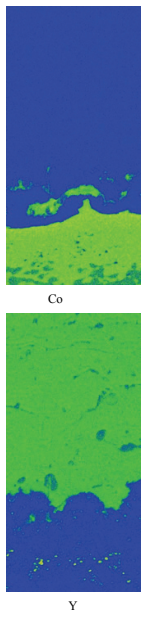
bond coat, key coat, TGO and TBC (b) process, possibly between the $1 \mathrm{~h}$ and $10 \mathrm{~h}$ samples; a significant number are observed after $100 \mathrm{~h}$ ageing. Figure 6 shows an SEM image of the system for each 'short' ageing time together with Long Term Oxidation: After ageing for much longer times of $2,000 \mathrm{~h}$ and $10,000 \mathrm{~h}$ the main difference between the two that the oxide scale has continued to grow. The 10,000 oxide scale is significantly thicker than that seen on the $2,000 \mathrm{~h}$ of the key coat and appears to have progressed into the bond coat slightly as well.

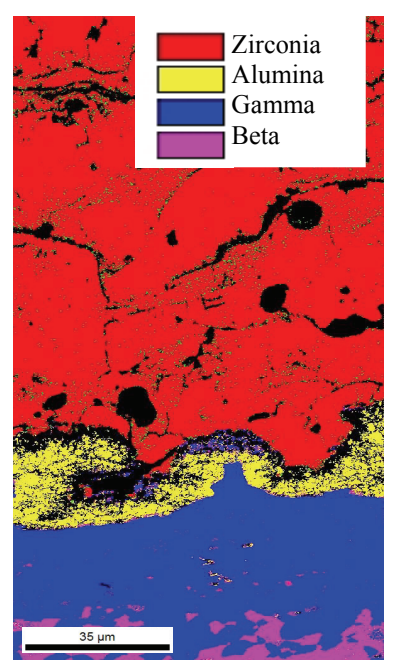

(c) Figure 8: EBSD scan of a NiCoCrAlY bond coat/TBC interface sample aged for $2000 \mathrm{~h}$ at $940^{\circ} \mathrm{C}$ showing (a) grain structure of the b) EDX maps (c) phase map

After $100 \mathrm{~h}$ the oxide layer is much thicker $(>5 \mu \mathrm{m})$ and the $\beta$ depletion layer is now almost the size of the key coat $(\sim 30-40$ $\mu \mathrm{m})$. There is some evidence of multi-oxide/spinel phases above the TGO after $10 \mathrm{~h}$ and precipitates within the main body of the TGO appear to be forming from very early on in the ageing
The precipitates within the main TGO are still present (Figure 7(a)), and are spread out through the oxide layer and don't appear to be clustered in any particular way. The multi-oxide/spinel phases on the top side of the TGO have increased significantly in size although they are not prevalent throughout the sample, rather 
scattered throughout at lengthy intervals. Figure 7c shows an EDX map of the sample aged for $2000 \mathrm{~h}$ at $940^{\circ} \mathrm{C}$ and clearly shows the $\beta$ depletion layer at the key coat/TBC interface. The main TGO is aluminium rich, and presumably alumina, however the precipitates within the TGO are too small to quantify due to the spatial resolution of the technique within the SEM. The multioxide/spinel regions appear to be one of two things. They are either bond coat particles which appear to be in the TBC layer due to orientation, and that have been completely encircled with alumina growth. The lack of aluminium in the particle may then have led to chromium oxide formation (presumably chromia) along the inside edge of the alumina. The other possibility is that the multi-oxide/spinel phases seen in after short term ageing on the top edge of the oxide have increased in size; these are rich in $\mathrm{Ni}, \mathrm{Al}, \mathrm{Co}$ and $\mathrm{Cr}$.

An EBSD map from a NiCoCrAlY bond coat/TBC interface sample aged for $2000 \mathrm{~h}$ at $940^{\circ} \mathrm{C}$ is presented in Figure 8. EBSD analysis has shown that the grain structures of the bond coat and key coat have become much more homogeneous after ageing. The grain structures present in the TGO are quite small, with grains ranging from $\sim 5 \mu \mathrm{m}$ down to $<1 \mu \mathrm{m}$ in size. The chromium-rich section of the oxide appears to have an even smaller grain size, although there are also some fine regions apparent in the alumina also. The grain structure of the TBC can again seen to be extremely complicated, as noted previously. It can be seen that, as noted on the unaged samples, there is a vast disparity in the grain size within the TBC, mainly due to the thermal spray process and the 'molten splat' structure.
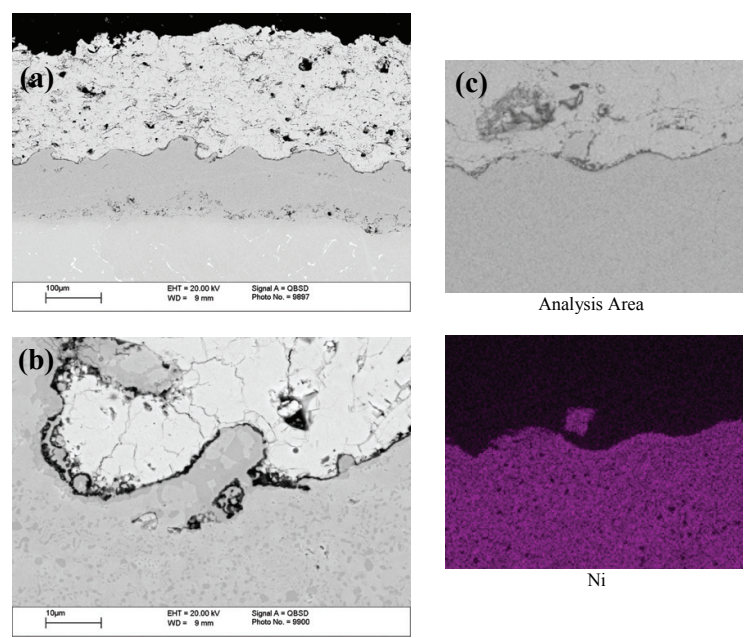

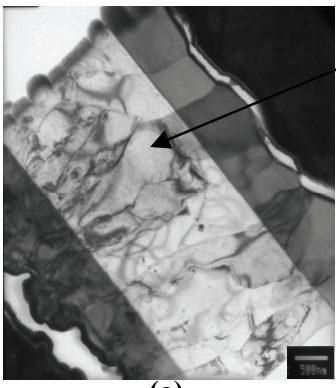

(a)

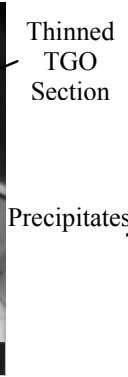

Figure 9: TEM images of a NiCoCrAlY sample aged for $2000 \mathrm{~h}$ at $940^{\circ} \mathrm{C}$ showing (a) overview of the FIB sample taken across the TGO layer (b) precipitates within the TGO

EDX analysis of these precipitates showed that some appeared to be yttrium aluminium garnet (YAG) particles whereas others were combinations of $\mathrm{Co}, \mathrm{Cr}, \mathrm{Al}, \mathrm{Ni}, \mathrm{Y}, \mathrm{Zr}$.

\section{$\underline{\mathrm{NiCrAlY}}$}

Unaged: An overview of the NiCrAlY system showing the various layers can be seen in Figure 10. The NiCrAlY samples do not utilise a key coat, unlike the NiCoCrAlY samples. The contrast within the backscattered images, indicates that there are at least two phases present. Chemical composition maps are presented in Figure 10c. However, from the EDX map of $\mathrm{Cr}$ in particular, it can be seen that there is a bright phase rich in $\mathrm{Cr}$ throughout the bondcoat which is likely to be the $\alpha-\mathrm{Cr}$ phase,
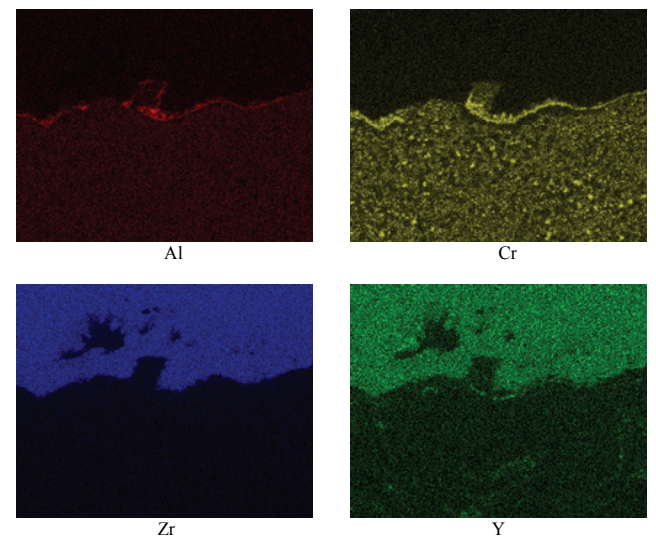

Figure 10: An unaged NiCrAlY bond coat/TBC interface region (a) and (b) Backscattered SEM images (c) chemical composition map

However, compared with the unaged sample, the aged samples appear to show a greater number of fine grained regions within the TBC suggesting that there may be some grain growth taking place. The TBC is effectively being sintered at these high temperatures. For higher resolution examination of the microstructure, a TEM sample was made from the TGO (Figure 9). The resultant grain structures determined from this sample correlated well with those obtained from EBSD, i.e. grain sizes of $\sim 1-5 \mu \mathrm{m}$, and precipitates appearing primarily at grain boundaries. together with two other regions which contain smaller and different amounts of $\mathrm{Cr}$. The matrix phase was found to be high in $\mathrm{Co}, \mathrm{Cr}$ and $\mathrm{Ni}$ and the second phase higher in aluminium. Consistent with the EBSD map presented in Figure 4, it is likely that these are regions of $\gamma^{\prime}$ and $\beta$ respectively. Under these imaging conditions, it would appear that it is not possible to distinguish between the $\beta$ and $\gamma^{\prime}$ phases due to insufficient atomic number contrast. 
The bond coat thickness $(\sim 90 \mu \mathrm{m})$ is in general much less than that of the NiCoCrAlY sample, however, the surface roughness is significantly greater, with large undulations along the length of the sample. The TBC also appears to contain a network of cracks together with the presence of some voids, as was the case for the NiCoCrAlY sample. Throughout the unaged sample small regions of oxide were present. These were found to be a combination of both aluminium and chromium rich oxides, which appear in short lengths along the bond coat/TBC interface, and are not continuous. EBSD analysis was used to analyse the grain structures at the bond coat/TBC interface in a similar manner to that for the NiCoCrAlY sample. The bond coat was again observed to have a variable grain size and the TBC was also extremely heterogeneous.
Short Term Oxidation: The NiCrAlY samples were isothermally aged at $940^{\circ} \mathrm{C}$ for $1 \mathrm{~h}, 10, \mathrm{~h}$ and $100 \mathrm{~h}$. Figure 11 presents SEM images for each of these ageing times, together with a representative EDX composition map for the sample aged for 10 h. It can be seen that significant changes occur on ageing. After 1 $\mathrm{h}$, an oxide layer has began to form along the bond coat/TBC interface. However, unlike that found in the NiCoCrAlY sample this oxide is chromium rich, presumably chromia. This oxide is also a bit thicker than that seen in the NiCoCrAlY sample, being $\sim 1-5 \mu \mathrm{m}$ in thickness depending on location. There also appears to be a small depletion of the $\alpha-\mathrm{Cr}$ phase from within the bond coat, directly underneath the bond coat/TBC interface.
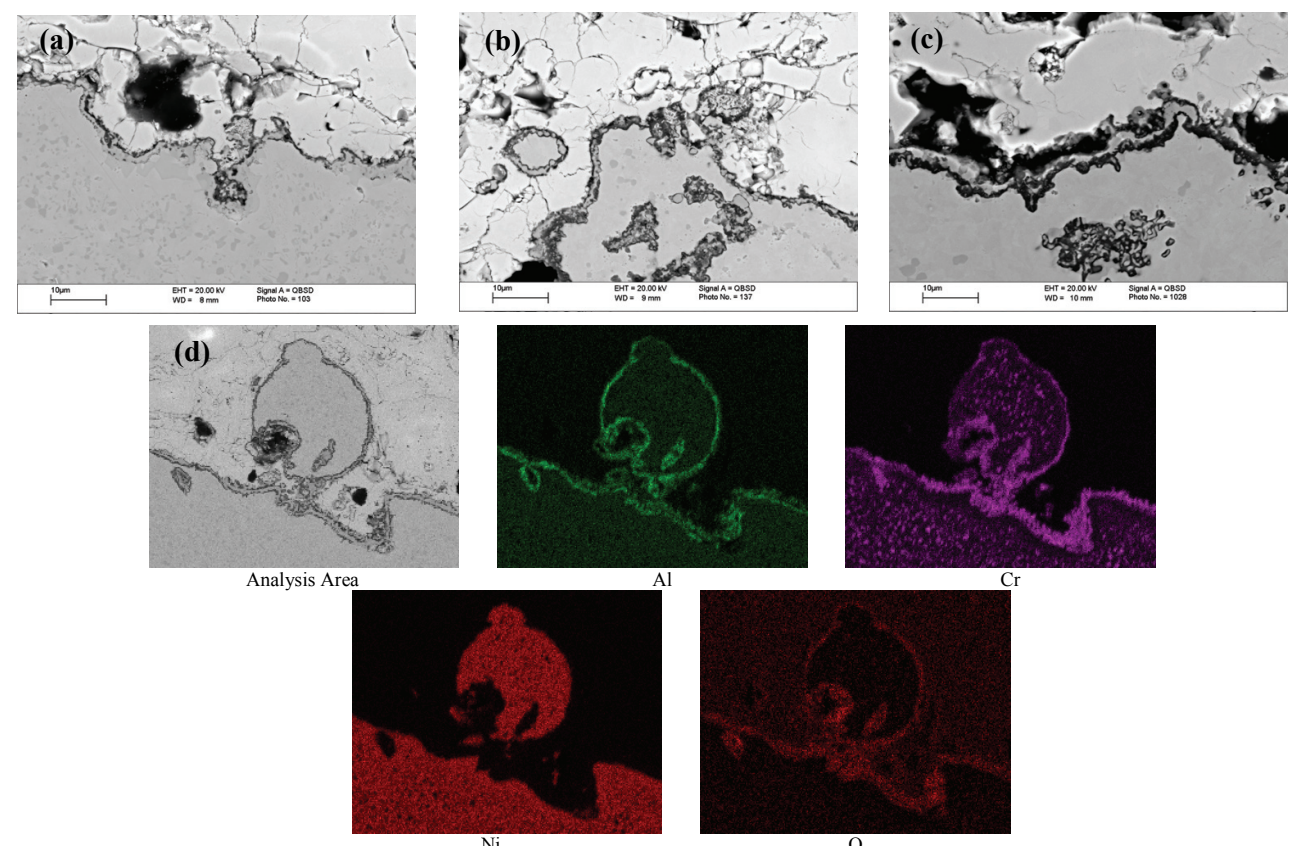

Figure 11: Backscattered SEM images showing a NiCrAlY sample aged for (a) $1 \mathrm{~h}$ (b) $10 \mathrm{~h}$ (c) $100 \mathrm{~h}$ and (d) chemical composition maps of the $10 \mathrm{~h}$ sample
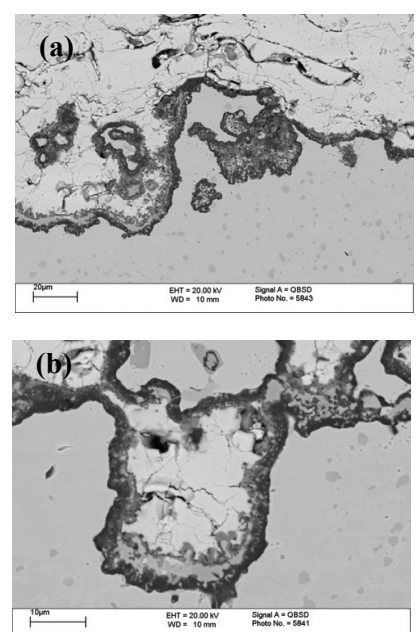
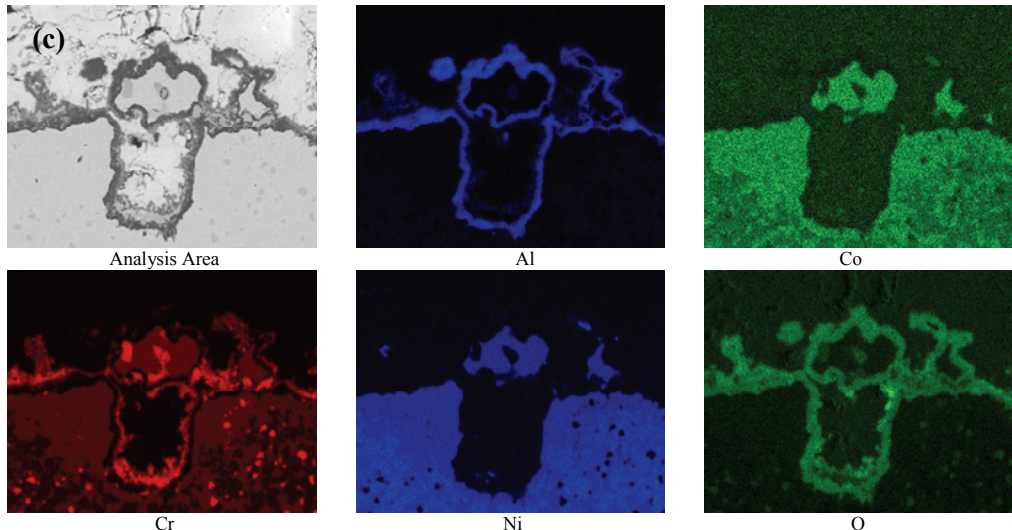

Figure 12: A NiCrAlY bond coat/TBC interface region aged for $2000 \mathrm{~h}$ at $940^{\circ} \mathrm{C}$ (a) and (b) Backscattered SEM images (c) chemical composition map 
After $10 \mathrm{~h}$ the chromium oxide has grown rapidly and now varies between 2 and $10 \mu \mathrm{m}$ thick, depending on location. Below this chromia layer, a layer of aluminium oxide (presumably alumina) has begun to form; this layer is between $0.5 \mu \mathrm{m}$ and $1 \mu \mathrm{m}$ in thickness. The chromium depletion in the bond coat has now left a definitive depleted layer below the interface with the majority of the $\alpha-\mathrm{Cr}$ disappearing from this region. The $\mathrm{Cr}$ concentration was also observed to be depleted from the $\gamma^{\prime}$ matrix. There does not appear to be a significant aluminium depletion zone after $10 \mathrm{~h}$, however, after $100 \mathrm{~h}$ the alumina layer has increased in thickness up to $\sim 2 \mu \mathrm{m}$ and an aluminium depletion zone is clearly visible. the precipitates within the alumina TGO are too small to quantify with EDX in the SEM. The $\beta$ phase is very hard to distinguish as discussed previously, however it is possible to discern using local composition measurements that there is indeed a $\beta$ depletion zone directly beneath the alumina TGO. Figure 13 shows an EBSD map of a bond coat/oxide/TBC interface region. The bond coat grain structure has become much more homogeneous. The alumina grain size is quite small with grains ranging from 1-5 $\mu \mathrm{m}$, however, the chromia regions of TGO show an even smaller grain size of $1 \mu \mathrm{m}$ and below, which are challenging the resolution of the EBSD system. The TBC continues to show a large variation in

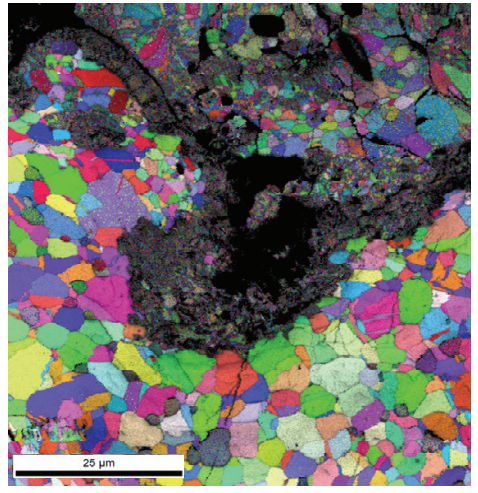

(a)

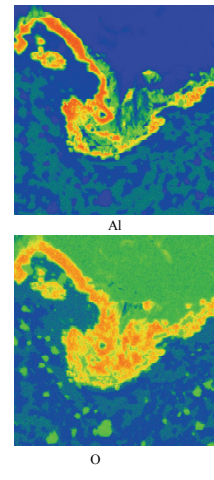

(a)
Figure 13: EBSD scan of a NiCrAlY sample aged for $2000 \mathrm{~h}$ at $940^{\circ} \mathrm{C}$ showing (a) grain structure of the bond coat, key coat, TGO and

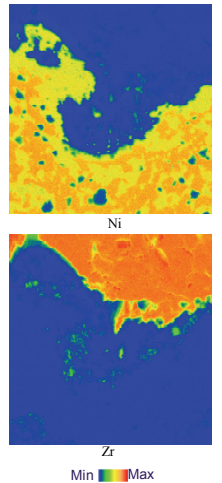

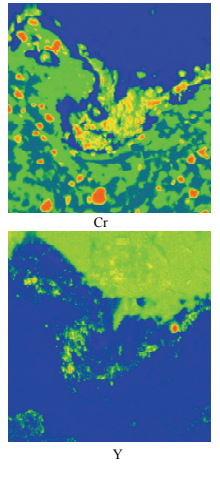

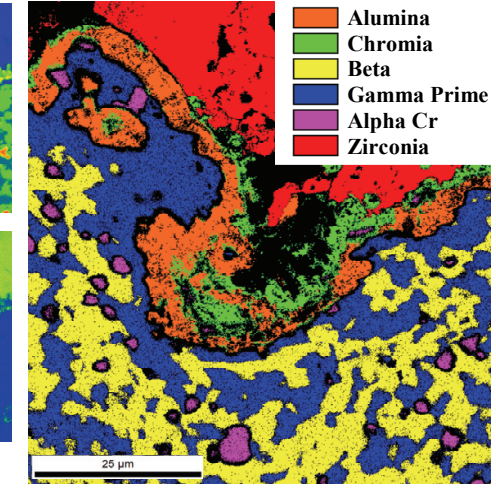

(c) TBC (b) EDX maps (c) phase map

The NiCrAlY samples appeared to contain only the two distinct layers of chromia and alumina, and unlike in the NiCoCrAlY samples, no multi-oxide/spinel larger regions were present. However, as in the NiCoCrAlY samples, fine precipitates were present within the alumina TGO, although they appear greater in number in this case and are more prevalent throughout the sample. These fine precipitates appear to be forming between $10 \mathrm{~h}$ and $100 \mathrm{~h}$.

Long Term Oxidation: After ageing for longer times of 2,000 h and $10,000 \mathrm{~h}$, the oxide growth has continued. The alumina layer is now much thicker overall, although the chromia TGO appears to have either slowed down significantly or has stopped growing altogether. It was noted that the total oxide thickness measured from the samples actually appears to be slightly smaller after $10,000 \mathrm{~h}$ compared to $2,000 \mathrm{~h}$ of ageing. The TBC was observed to be still attached to the samples, and therefore it seems unlikely that there has been significant oxide spallation.

After ageing, a significant $\beta$ depletion zone was observed beneath the oxide interface, together with a reduction in the number of $\alpha$ $\mathrm{Cr}$ particles present in the bond coat. The precipitates within the alumina TGO are still present and are widely spread throughout the oxide. Figure 12 presents SEM images and a composition map for the sample aged for $2,000 \mathrm{~h}$ at $940^{\circ} \mathrm{C}$. It can also be seen that there are no signs of any large multi-oxide/spinel phases within the sample. Both the $2,000 \mathrm{~h}$ and $10,000 \mathrm{~h}$ samples show the same microstructural trends with no significant differences between them. Figure 12c shows an EDX map of a 2,000 h sample aged at $940^{\circ} \mathrm{C}$ which clearly shows the dual layer oxide growth comprising of both chromia and alumina. As with the NiCoCrAlY grain size throughout. In order to examine the TGO at higher resolution, a TEM sample was made to encompass both the alumina and chromia regions. Figure 14 shows that the alumina contains some grains of $\sim 1 \mu \mathrm{m}$ in size but there are some very fine grained regions present also. The chromia region shows smaller grains in general than the alumina regions, $\sim 0.5 \mu \mathrm{m}$. EDX analysis in the TEM showed the alumina to consist of $\mathrm{Al}$ and $\mathrm{O}$ in ratios consistent with the formula $\mathrm{Al}_{2} \mathrm{O}_{3}$. It was interesting to note that the regions thought to be chromia indicated $\mathrm{Cr}$ and $\mathrm{Al}$ traces only. It is possible that the $\mathrm{O} X$-ray lines are being absorbed by the dense $\mathrm{Cr}$ rich region, which requires further investigation.

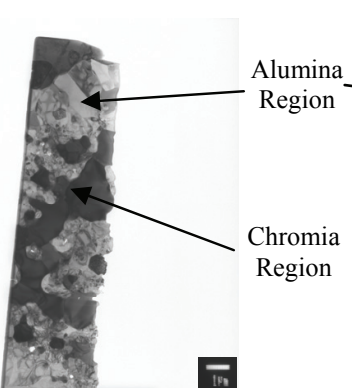

(a)

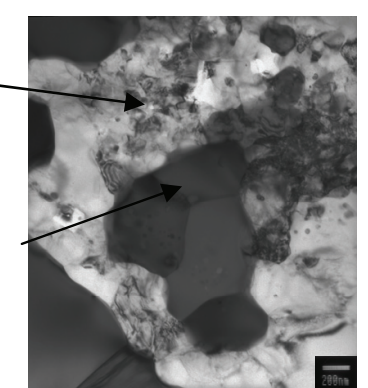

(b)
Figure 14: TEM images of a NiCrAlY sample aged for $2000 \mathrm{~h}$ at $940^{\circ} \mathrm{C}$ showing (a) overview of the FIB sample taken across the TGO layer (b) higher magnification image showing the chromia regions in the TGO 


\section{Discussion}

The thermodynamic calculations have provided valuable insight into the phase stability of the two different types of overlay coatings. Although the thermodynamic data used in this work are generally applied to Ni-based superalloys with a high volume fraction of $\gamma^{\prime}$, the agreement between the phases predicted to be present in the coatings and the experimental phase discrimination using a combination of EBSD and EDX is excellent. In addition to the relative amounts of the phases present, their chemical compositions measured using EDX analysis in both the SEM and TEM have been shown to be in reasonably good agreement with the predicted phase compositions. It has been shown that there is a significant difference between the phase stability of the NiCoCrAlY coating, which contains primarily $\gamma$ and $\beta$ phases, and the NiCrAlY coating which instead comprises, at lower temperatures, $\gamma^{\prime}$ and $\alpha-\mathrm{Cr}$. The transformation to $\gamma^{\prime}$ and $\alpha-\mathrm{Cr}$ has been previously shown to affect the ductile-brittle transition temperature of such overlay coatings, and also results in a change in the thermal expansion coefficient. The increasing $\mathrm{Co}$ concentration can be seen to stabilise the $\gamma$ phase to lower temperatures, alter the relative proportions of the $\gamma$ and $\beta$ phases and also to stabilise the $\sigma$ phase compared to $\alpha-\mathrm{Cr}$.

The oxidation mechanisms for these types of MCrAlY coatings depend on a number of factors, which include not only the phase type, composition and distribution, but also the presence of reactive elements, processing parameters and any effects from interdiffusion with the substrate. The two MCrAlY bond coats investigated in this research were of considerable difference in thickness, with the NiCoCrAlY being relatively thick $(\sim 250 \mu \mathrm{m})$ and the NiCrAlY coating being much thinner $(\sim 90 \mu \mathrm{m})$. These differences in thickness are likely to have the most significant effect at longer ageing times, where interdiffusion between the coating and the substrate will become important, although clearly the supply of elements to form the protective oxide scale will differ simply because of the difference in starting amounts. Both were deposited onto the same In738 substrate. There were also differences in the initial surface roughness of the coatings. The NiCoCrAlY bond coat was relatively uniform, with a reasonably low surface roughness, whereas the NiCrAlY bond coat had a much greater surface roughness, and has more variation in thickness around the sample surface. The surface roughness of a bond coat has been previously shown to influence the oxidation behaviour of that bond coat ${ }^{[17]}$, in which a difference in the nature of the oxides formed was observed between an as sprayed and a polished surface for a NiCoCrAlYRe coating. The as sprayed coating was found to comprise of an alumina layer, together with chromia and spinel formation above, whereas the polished coating led primarily to the formation of an alumina scale.

The two coatings show distinctly different oxide formations after ageing, both after short and long time periods. The NiCoCrAlY coating was observed to form a continuous alumina scale, whereas the NiCrAlY coating formed a dual layer oxide comprising of both alumina and chromia. The NiCrAlY coating comprised of the $\gamma^{\prime}$ and $\alpha$-Cr phases, and the formation of chromia rather than alumina initially indicates that chromium supply was easier in this case. The chromia layer was observed to form fairly rapidly initially, followed by an alumina layer below the chromia, which continued to thicken after the chromia had stopped growing.
It is clear, therefore, that upon initial (transient) oxidation the oxide which forms is different between the two bond coats. Transient oxidation on a NiCrAl bond coat has been described to comprise of three stages: the initial oxide contains all the cations of the immediate alloy surface, which is followed by formation of $\mathrm{Cr}_{2} \mathrm{O}_{3}$ subscale due to its stability at the low oxygen activity, which is in turn followed by internal $\mathrm{Al}_{2} \mathrm{O}_{3}$ layer which is stable at even lower activities ${ }^{[18]}$. The continuous $\mathrm{Cr}_{2} \mathrm{O}_{3}$ subscale can reduce oxygen diffusion and slow internal $\mathrm{Al}_{2} \mathrm{O}_{3}$ formation. However, eventually the $\mathrm{Al}_{2} \mathrm{O}_{3}$ subscale becomes continuous and rate controlling.

The growth mechanisms of most oxides on MCrAlY systems are considered to be cation diffusion controlled i.e. metal ion diffusion to the interface, however it is clear that in the NiCrAlY system although the chromia may be forming from this mechanism (or at least a mixture of cation and anion diffusion), once the chromia is formed, the alumina layer below must be forming from inward oxygen anion diffusion. This means that the scale growth is controlled by the inward transport of $\mathrm{O}$ ions ${ }^{[12,19-20]}$ leading to a reduction in the parabolic oxidation rate constant and hence scale growth. In the NiCoCrAlY system, however, where the oxide growth is probably cation controlled, or at least a mixture of cation and anion diffusion, the oxidation rate could be assumed to be higher.

\section{Conclusions}

This research has demonstrated the importance of thermodynamic calculations to provide an indication of coating phase stability. In turn, advanced analytical electron microscopy techniques including the combined use of EBSD and EDX for phase discrimination, and the preparation of site-specific TEM samples using a FIBSEM, have been used to compare the oxides formed on two different bond coat systems after short and longer term isothermal ageing. It has been clearly shown that the coating composition affects the type of oxide which is formed, in addition to changing the oxide growth rates, morphologies and the presence and nature of fine precipitates forming within the TGO. The NiCoCrAlY coating formed an alumina TGO, together with various spinel phases, whereas the NiCrAlY sample also contained a thick layer of chromium rich oxide. Fine scale precipitates, probably YAG (Yttrium Aluminium Garnet), were identified in both alumina TGO's. The use of EBSD and TEM has demonstrated that the grain structures of the TGO's were extremely fine, and furthermore that the TBC itself is extremely complex and heterogeneous. The results have important implications for the modelling of lifetime of protective coatings, particularly in the sequence, nature and rate of formation of the oxides which form as a function of chemical composition and ageing temperature. 


\section{References}

1. Sims CT, Stoloff NS and Hagel, WC. Superalloys II 1987, New York, USA: John Wiley \& Sons.

2. Evans AG, Mumm DR, Hutchinson JW, Meier GH, Petit FS. Mechanisms controlling the durability of thermal barrier coatings. Prog. Mater. Sci. 46. 2001. 505-553.

3. Nicholls JR, Simms NJ, Chan WY, Evans HE. Smart overlay coatings - concept and practice. Surface and Coatings Technology. 149. 2002. 236-44.

4. Burns AJ, Subramanian R, Kempshall BW, Sohn YH. Microstructure of as-coated thermal barrier coatings with varying lifetimes. Surf. Coat. Technol. 117-178. 2004. 8996.

5. Konter M, Thumann M. Materials and manufacturing of advanced industrial gas turbine components. J. Mater. Process. Technol. 117. 2001. 386-90.

6. Wang B, Gong, J. Sun, C., Huang, R. F. and Wen, L. S. The behaviour of $\mathrm{MCrAlY}$ coatings on $\mathrm{Ni}_{3} \mathrm{Al}$-base superalloy. Mats. Sci and Eng. A357. 2003. 39-44.

7. Sarioglu C, Stinner C, Blachere JR, Birks N, Pettit, F. S. and Meier, G. H. The control of sulphur in nickel-base, single crystal superalloys and its effects on cyclic oxidation resistance. Proceedings of Superalloys 1996, eds. RD Kissinger, DJ Deye, DL Anton, AD Cetel, MV Nathal, Pollock, T. M. and Woodford, DA, The Minerals, Metals \& Materials Society 1996, 71-80.

8. Chevalier S, Przybylski K, Borchardt, G. and Larpin, J. P. Role of minor element addition in the formation of thermally grown alumina scales. Mater. Sci. Forum. 461464. 2004. 53-60.

9. Toma D, Brandl, W. and Koster, K. The characteristics of alumina scales formed on HVOF-sprayed MCrAlY coatings. Oxid. Met. 53. 2000. 125-37.

10. Pomeroy MJ. Coatings for gas turbine materials and long term stability issues. Mater Des. 26. 2005. 223-31.

11. Pint BA. Experimental observations in support of the dynamic-segregation theory to explain the reactive-element effect. Oxid. Met. 45. 1996. 1-37.

12. Wright, IG and Pint, BA Bond coating issues in thermal barrier coatings for industrial gas turbines. Presented at Proceedings of the Institute of Mechanical Engineers, Part A Journal of Power and Energy, 2005, 219. 2005. 101-107.

13. Christensen RJ, Tolpygo, VK and Clarke, DR. The influence of reactive element yttrium on the stress in alumina scales formed by oxidation. Acta. Mater. 45. 1997. $1761-1766$
14. Hampikian JM. The effects of reactive element, ionimplantation-induced amorphous layers on the oxidation of Co-12Cr and ni-12Cr alloys. Oxid. Met. 50. 1998. 123-38.

15. Davies RH, Dinsdale AT, Chart TG, Barry TI, Rand MH. High. Temp. Sci. 26. 1989. 251-262.

16. Saunders N. Phase Diagrams Calculations for Ni-based Superalloys Proceedings of Superalloys 1996, Eds. R. Kissinger D. J. Deye, D. L. Anton, A. D. Cetel, M. V. Nathal, T. M. Pollock and D. A. Woodford ed. The Minerals, Metals \& Materials Society, 1996, 101-110

17. N. Czech, M. Juez-Lorenzo, V. Kolarik and W. Stamm., "Influence of the surface roughness on the oxide scale formation on MCrAlY coatings studied in situ high temperature X-ray diffraction," Surface and Coatings Technology, (108-109) (1998), 36-42.

18. Sims CT, Stoloff NS and Hagel, WC, Superalloys II (New York, USA: John Wiley \& Sons. 1987), 302-3.

19. Cao XQ, Vassen, R. and Stoever, D. 2004. Ceramic materials for thermal barrier coatings. J. Eur. Ceram. Soc. $24: 1-10$.

20. Gurrappa I. 2001. Identification of hot corrosion resistant MCrAlY based bond coatings for gas turbine engine applications. Surface and Coatings Technology. 139 : 27283.

\section{Acknowledgements}

The authors would like to acknowledge the financial support of both EPSRC and RWE npower for this research project. 